Check for updates

Cite this: J. Mater. Chem. C, 2021, 9, 16057

DOI: $10.1039 / d 1 t c 90234 b$

rsc.li/materials-c

\section{Introduction to the themed issue in honour of Prof. Kees Hummelen}

\author{
Hennie Valkenier, (D) ${ }^{a}$ Dirk Vanderzande, (D) ${ }^{b}$ Andries Meijerink (D) ${ }^{c}$ and \\ Maurizio Prato (D) de
}

In this issue of Journal of Materials Chemistry $C$, we honour Prof. Dr. Jan Cornelius Hummelen, better known as Kees Hummelen, on the occasion of his retirement. Kees is an organic chemist by training, with a very broad interest in all different disciplines of science (and beyond), as can be read in the biographical

\footnotetext{
${ }^{a}$ Université Libre de Bruxelles (ULB), Engineering of Molecular NanoSystems, École polytechnique de Bruxelles, Avenue F.D. Roosevelt 50, CP165/64, B-1050 Brussels, Belgium. E-mail: Hennie.Valkenier@ulb.be

${ }^{b}$ Hasselt University (UHasselt) and imec, imo-imomec, Faculty of Science, Martelarenlaan 42, B-3500 Hasselt, Belgium. E-mail: Dirk.vanderzande@uhasselt.be

${ }^{c}$ Utrecht University, Debye Institute for Nanomaterials Science, Faculty of Science, Princetonplein 1, 3584 CC Utrecht, The Netherlands. E-mail: a.meijerink@uu.nl

${ }^{d}$ University of Trieste, Department of Chemical and Pharmaceutical Sciences, Via Giorgieri 1, Trieste, Italy.E-mail:prato@units.it

${ }^{e}$ CIC biomaGUNE, San Sebastián, Spain
}

contribution by his friend and colleague Bert Meijer (DOI: 10.1039/D1TC90193A). In the last 25 years, Kees has worked on the application of organic compounds in molecular materials and devices for organic electronics.

Kees' passion for fullerenes dates back to the days he spent in the lab of Fred Wudl in Santa Barbara (see also DOI: 10.1039/D1TC90194J), where he developed PCBM, a $\mathrm{C}_{60}$ derivative with improved solubility that turned out to work surprisingly well as an electron acceptor in organic photovoltaics. ${ }^{1}$ This compound and its properties have played a central role in the rest of Kees' career as Professor of Organic Chemistry at the University of Groningen, but also in his company on fullerene adducts. He has developed numerous fullerene derivatives, including analogues of PCBM, and studied the impact of the structural variations on the performance of these fullerenes in devices. For this, he collaborated with many physicists and engineers, both at the University of Groningen and outside. A clear example of such a study is found in this issue, where the impact of the length of an oligo(ethylene-glycol) chain of a fullerene derivative on the crystallisation properties and charge-carrier mobility is presented (DOI: 10.1039/D1TC02753K).

Although efficiencies in organic photovoltaic devices have been strongly improved by the introduction of so-called nonfullerene acceptors, fullerenes developed by Kees remain as interlayers in different types of devices or as part of a ternary blend with a non-fullerene acceptor, as presented in this issue (DOI: 10.1039/ D1TC02241E). Kees has also been part of strong collaborations probing new concepts towards single-component organic solar cells, for example double cable conjugated polymers. This challenging concept, in which donor and acceptor structures are incorporated in a single molecular structure, avoiding in this way detrimental phase
Hennie Valkenier first joined the laboratory of Kees Hummelen for her Bachelor's research project in 2004 and continued her Master's and PhD research in the field of molecular electronics under Kees' supervision. She obtained her PhD degree from the University of Groningen in 2011. After 3 years of postdoctoral research in supramolecular chemistry at the University of Bristol, she moved to Belgium, where she joined the Engineering of Molecular NanoSystems laboratory at the Universite Libre de Bruxelles. She received an ERC starting grant in 2018 and works with her team on the development of ion receptors for transmembrane transport.
Dirk Vanderzande obtained his PhD in Chemistry at KU Leuven in 1986 and moved to UHasselt (Belgium) for a permanent position starting in 1987. In 1988, he started his research in the field of low bandgap conjugated polymers and the synthesis of poly(arylene vinylene) derivatives. In 1999, his research moved toward materials for organic solar cells, which was a starting point for building a close collaboration with Kees Hummelen. In 2003, he was appointed as Full Professor (Gewoon Hoogleraar) at UHasselt. In October 2010, he took up the position of director of the Institute for Materials Research "imo-imomec" (UHasselt/imec). 
separation, has witnessed quite some hurdles. Nevertheless, it is still being pursued and examples with remarkable efficiencies have surfaced (DOI: 10.1039/ D1TC01195B). In addition, Kees pioneered new avenues for enhancing solar efficiencies by discovering the dye-sensitization of upconversion in lanthanide-doped nanocrystals. Since his successful demonstration of this process, ${ }^{2}$ the field has rapidly grown as also demonstrated in this issue (DOI: 10.1039/D1TC02441H and 10.1039/ D1TC03333F).

Apart from his research on fullerenes and their applications in organic electronics, Kees was also fascinated by the principles of $\pi$-conjugation and the effect that conjugation patterns could have on the electronic properties of single molecules. Kees' ideas that patterns of alternating single and double bonds could impact the conductance properties of pathways within a molecule ${ }^{3}$ were received with a lot of skepticism at the time. It was great to see that the impact of cross-conjugation on conductance could be observed experimentally by different methods ${ }^{4}$ and some of the ideas that Kees proposed 'too early' are now more widely accepted. ${ }^{5}$ Accurately measuring the conductance of various electronic pathways within a single molecule remains a great challenge, which is nicely demonstrated by the contribution of González and co-workers to this themed issue (DOI: 10.1039/D1TC02753K). Thus, while Kees demonstrated the relevance of chemical intuition for molecular electronics, a lot more work needs to be done before we can find real-life applications of pi-logic.

In the course of these years, Kees has disseminated science and friendship. His friends now honour him with contributions collected in this themed issue, clearly demonstrating that science is a forum where ideas grow and mature, while creating a perfect environment to establish a community with solid relationships and human respect.

\section{References}

1 J. C. Hummelen, B. W. Knight, F. LePeq, F. Wudl, J. Yao and C. L. Wilkins, J. Org. Chem., 1995, 60, 532-538.

2 W. Zou, C. Visser, J. A. Maduro, M. S. Pshenichnikov and J. C. Hummelen, Nat. Photonics, 2012, 6, 560-564.

3 M. H. van derVeen, M. T. Rispens, H. T. Jonkman and J. C. Hummelen, Adv. Funct. Mater., 2004, 14, 215-223; M. H. van der Veen, 'pi-Logic', $\mathrm{PhD}$ thesis, University of Groningen, Groningen, 2006.

4 H. Valkenier, C. M. Guédon, T. Markussen, K. S. Thygesen, S. J. van der Molen and J. C. Hummelen, Phys. Chem. Chem. Phys., 2014, 16, 653-662.

5 T. Stuyver, S. Fias, F. De Proft and P. Geerlings, J. Phys. Chem. C, 2015, 119, 26390-26400; J. Gu, W. Wu, T. Stuyver, D. Danovich, R. Hoffmann, Y. Tsuji and S. Shaik, J. Am. Chem. Soc., 2019, 141, 6030-6047.
Andries Meijerink received his MSc and PhD degrees in Chemistry at Utrecht University. After a post-doc in Madison (University of Wisconsin), he returned to Utrecht in 1991. In 1996, he was appointed as Professor of Solid State Chemistry in the Debye Institute of Utrecht University, where he leads an active group in the field of the luminescence spectroscopy of quantum dots and lanthanide ions. In recent years, he has worked closely with Kees Hummelen on dye-sensitized upconversion in nanocrystals for various applications.
Maurizio Prato is a professor of organic chemistry in Trieste, Italy and Ikerbasque Professor at CIC biomaGUNE, Spain. His research interests lie mainly in the synthesis and application of organic compounds to materials science and medicine, in particular using carbon allotropes such as fullerenes, carbon nanotubes, graphene and, more recently, carbon nanodots. He was a research associate in Fred Wudl's lab when Kees arrived in Santa Barbara. The two got along very well, sharing the lab life and the challenge of azide additions to $C_{60}$. From there, Kees started his "fullerene way" in the smartest possible way, i.e., by synthesising the first azafullerene. 